\title{
MOLEKUL
}

Articles

\section{Antioxidant Compounds from The Stem Bark of Syzygium samarangense L}

\author{
Seni Metasari ${ }^{1}$, Elfita ${ }^{2}$, Muharni $^{2}$, Heni Yohandini ${ }^{2}$ \\ 'Magister Program of Chemistry, Department of Chemistry, Faculty of Mathematics and Natural Sciences, \\ University of Sriwijaya, Palembang, South Sumatra, 30662 Indonesia \\ ${ }^{2}$ Department of Chemistry, Faculty of Mathematics and Natural Sciences, University of Sriwijaya, Inderalaya, \\ Ogan Ilir, South Sumatra, 30662 Indonesia
}

*Corresponding author email: elfita69@gmail.com

Received December 19, 2019; Accepted October 15, 2020; Available online November 20, 2020

\begin{abstract}
Ogan ethnic community in South Sumatera has been used a decoction of the stem bark of Syzygium samarangense $L$ (locally named "jambu air" in Indonesia) for hypertension medicine. Hypertension is a degenerative disease caused by free radical activity in the body. This study aims to scientifically prove the use of a decoction of the stem bark of $S$. samarangense so that its use by the Ogan ethnic community can be justified. The research began with fractionation of the stem bark by gradient solvents, and each fraction was tested for antioxidant activity. Isolation of antioxidant compounds from active fractions was carried out by chromatographic techniques. Antioxidant tests on fractions and pure compounds were carried out by the 2,2diphenyl-1-picrylhydrazyl (DPPH) method. Based on spectroscopic data analysis and by comparing with literature, the pure compounds were identified as quercetin and gallic acid. Both of these compounds have strong antioxidant activity with $\mathrm{IC}_{50}$ quercetin 11.16 and gallic acid $11.43 \mu \mathrm{g} / \mathrm{mL}$. This research proves that the use of the stem bark of S. samarangense for a degenerative disease by the Ogan ethnic community contains the truth.
\end{abstract}

Keyword: antioxidant activity, gallic acid, quercetin, Syzygium samarangense,

\section{INTRODUCTION}

An ethnomedicine survey conducted on the Ogan ethnic community in South Sumatra found that the stem bark of $S$. samarangense was used to treat hypertension. The use of the stem bark of S. samarangense as an antihypertension is related to the presence of antioxidant compounds found in these plants. The role of antioxidant compounds in reducing blood pressure for hypertensive patients is through inhibiting the work of enzymes that trigger an increase in blood pressure (Figueiredo et al., 2017; Loperena \& Harrison, 2017). In addition, the role of antioxidant compounds such as flavonoids as hypertension drugs is explained by their mechanism of binding of metal from hydroxyl groups at positions 3, 5, 7 and 3', 4' which can reduce systemic vascular resistance and the average blood pressure of diastoles and systole at various conditions of hypertension (Kizhakekuttu \& Widlansky, 2010; Widiasari, 2018).

Five species selected from Syzygium (S. aqueum, $S$. cumini, S. jambos, S. malaccense, and S. samarangense) from the leaves and stems were the best phenolic and flavonoid sources (Saxena, Saxena, Nema, Singh, \& Gupta, 2013; Chikezie, Ibegbulem, \& Mbagwu, 2015;
Shyamapada and Manisha, 2015; Nadeem, Abbasi, Younas, Ahmad, \& Khan 2017; Sheela and Cheenickal (2017). The ethanol extract of S. samarangense leaves was reported to contain myricetin 3-oxylosil- $(1 \rightarrow 2)$ rhamnoside, quercetin 3-oxylosil- $(1 \rightarrow 2)$ rhamnoside, gallic acid, and ethyl acetate extract containing 5, 7 dihydroxy 6,8-dimethyl flavanone. Furthermore, two hydrolyzed tannins were isolated from leaf extracts and showed potential anticancer activity in vitro, and four antioxidant compounds, namely dihydrochalcone, mirigalon $G$, mirigalon $B$, and phloretin 4-o-methyl (Yang et al., 2018; Jayasinghe, Ratnayake, Medawals, \& Fujimoto 2007). In Taiwan, S. samarangense flowers was used for therapeutic drugs for fever and diarrhea containing desmetoximateukinol and 5-o-methyl-4 'desmetoksimateukinol (Khandakar \& Boyce, 2016).

The chemical compounds report of the stem bark of S. samarangense is still limited. Gayen, Hossain, Saifuzzaman, \& Faroque (2016) reported the chemical content of ethanol extract from the stem bark of $S$. samarangense through phytochemical tests, namely tannins, flavonoids, saponins, and alkaloids. Naturally, chemical compounds found in every part of the plant such as bark, leaves, flowers, roots, fruits, and grains 
will show almost the same biological activity. In this paper, the stages of isolation of antioxidant compounds from the stem bark of $S$. samarangense are described. Obtaining these antioxidant compounds will prove the truth of the use of medicinal plants by an ethnic community and can also be developed as a source of potential antioxidant compounds in the future.

\section{EXPERIMENTAL SECTION}

Materials and Instrumentation

Fresh Stem bark of $S$. samarangense were collected in October 2018 from Tebing Gerinting, Ogan Ilir, South Sumatra, Indonesia, and identified at the Botany Laboratory, University of Sriwijaya. Materials for isolation: silica gel 60 (Merck, 70-230 mesh) was used for column chromatography, thin layer chromatography (TLC) was performed with silica gel 60G F254 using Merck (Art.5554), and organic solvents such as nhexane, ethyl acetate (E†OAc), and methanol $(\mathrm{MeOH})$ with technical grade. Reagent for antioxidant activity from Sigma-Aldrich: 2,2-diphenyl-1-picrylhydrazyl (DPPH), DMSO, and ascorbic acid. Instrumentation in the research were ${ }^{1} \mathrm{H}-\mathrm{NMR}$ and ${ }^{13} \mathrm{C}-\mathrm{NMR}$ spectra on Agilent DD2 ('H-500 MHz; ${ }^{13} \mathrm{C}-125 \mathrm{MHz}$ in $\mathrm{CD}_{3} \mathrm{OD}$ ).

\section{Fractionation of stem bark of $S$. samarangense}

The fresh stem bark of $S$. samarangense $(1.5 \mathrm{Kg})$ was cleaned and cut into small pieces. The sample is dried at room temperature until constant weight. Dry samples are milled to powder and macerated with gradient solvents such as n-hexane, ethyl acetate, and methanol. All filtrates were concentrated using a rotary evaporator to obtain concentrated extracts of the $n$-hexane, ethyl acetate, and methanol fractions (Muharni, Elfita, \& Amanda, 2011). Each fraction was tested for antioxidant activity by the DPPH method. The active fraction was continued to separation and purification until obtaining the pure compounds.

\section{Antioxidant activity test with DPPH method}

Antioxidant activity testing was carried out as reported before (Muharni et al., 2019; Budiono, Elfita, Muharni, Yohandini, \& Widjajanti, 2019). The DPPH solution $0.05 \mathrm{mM}$ (1.98 mg DPPH) was prepared in 100 $\mathrm{mL}$ methanol. The samples (extracts) were evaluated by dilution in methanol to obtain series concentrations of $1000,500,250,125,62.5,31.2 \mu \mathrm{g} / \mathrm{mL}$ and the pure compounds in series concentrations of 100, 50, 25, 12.5 , and $6.25 \mu \mathrm{g} / \mathrm{mL}$. The series concentrations of the sample $(0.2 \mathrm{~mL})$ were added $3.8 \mathrm{~mL}$ of DPPH solution. The mixture of solutions was homogeneous and allowed to react for 30 minutes at room temperature in dark conditions. Absorbance was measured by a UV-Vis spectrophotometer at $\lambda_{\max } 517 \mathrm{~nm}$. The positive control of ascorbic acid was used in the same treatment as the sample. The antioxidant activity of the samples were determined as the percentage of DPPH absorption inhibition and $I C_{50}$ value. The $\%$ inhibition according to the following equation:

$\%$ Inhibition $=\frac{\text { control absorbance }- \text { sample abrorbance }}{\text { control absorbance }} \times 100$

Isolation and purification of antioxidant compounds from active fraction

The active fraction was analyzed using thin layer chromatography (TLC) with various eluents. The concentrated $\mathrm{MeOH}$ fraction $(20 \mathrm{~g})$ was separated by vacuum column chromatography (VLC) $(20 \mathrm{~cm} \times 8 \mathrm{~cm})$ with silica gel (230-400 mesh) as a stationary phase. The pre-absorbed sample was put into a column and eluted by gradient solvents: $n$-hexane-EłOAc $(10: 0 \rightarrow 0: 10)$ and EtOAc-MeOH (10:0 $\rightarrow 0: 10)$. Eluates were analyzed with TLC to obtain four fractions $(F 1=3.45 \mathrm{~g} ; F 2=5.67 \mathrm{~g} ; F 3=4.38 \mathrm{~g}$; and $F 4=4.69 \mathrm{~g})$. Fractions F2 and F3 have potential stains and continued to separation and purification.

The F2 fraction $(5 \mathrm{~g})$ was chromatographed over silica gel column (70-230 mesh) and eluted by $\mathrm{n}$ hexane-EłOAc $(5: 5 \rightarrow 0: 10)$ and EłOAc-MeOH $(10: 0 \rightarrow 5: 5)$, which yielded four subfractions (F2.1F2.4). Fraction F2.2 (0.78 g) was subjected over a silica gel column with eluent of $n$-hexane-EtOAc (3:7) to give four fractions (F2.2.1-F2.2.4). Fraction F2.2.3 (63 mg) was subjected to purification to yield compound 1 $(21 \mathrm{mg})$. The F3 fraction $(4 \mathrm{~g})$ was chromatographed over silica gel column (70-230 mesh) and eluted by $n$ hexane-E†OAc $(5: 5 \rightarrow 0: 10)$ and EłOAc-MeOH $(10: 0 \rightarrow 5: 5)$ to obtain three subfractions (F3.1-F3.3). Fraction F3.2 $(0.98 \mathrm{~g})$ was subjected over a silica gel column with eluent of $n$-hexane-EtOAc $(2: 8)$ to obtain three fractions (F3.2.1-F3.2.3). Fraction F3.2.1 (89 mg) was subjected to purification to yield compound $\mathbf{2}$ $(67 \mathrm{mg})$. The structure of the compounds were identified by the spectroscopic method.

\section{RESULTS AND DISCUSSION}

The Fresh stem bark of $S$. samarangense $(1.5 \mathrm{~kg})$ after being dried, a constant weight of $978 \mathrm{~g}$, was obtained. Dry powder samples $(500 \mathrm{~g})$ have been extracted successively with $n$-hexane, ethyl acetate, and methanol for $1 \times 24$ hours with three replications to obtain concentrated fractions: $13.6 \mathrm{~g} ; 32.2 \mathrm{~g}$ and $20 \mathrm{~g}$ respectively for the $n$-hexane, ethyl acetate, and methanol fractions. Each of the fractions was tested for antioxidants as shown in Table 1.

Based on the $\mathrm{IC}_{50}$ value, the methanol fraction had the highest antioxidant activity among the three fractions ie, $31.83 \mathrm{ppm}$. The high antioxidant activity of the methanol fraction is due to to the presence of polar compounds such as phenolic compounds contained in 
that fraction. Flavonoids are sub-group of phenolic compounds have a variety of biological activities including antioxidant activity (Chandra \& Arora, 2017). The ability to antioxidant activity of phenolic compounds are influenced by chemical structure, number, and position of hydroxyl groups in the ring (Elfita, Supriyatna, Bahti, \& Dachriyanus, 2011). However, the antioxidant activity of ascorbic acid is higher because, in the methanol fraction, there is still a mixture of the compounds. The $\mathrm{n}$-hexane fraction is not active (IC50 value $>1000 \mu \mathrm{g} / \mathrm{mL}$ ). Elfita et al. (2019) state that the gradient fractionation causes non-polar and semi-polar compounds to be extracted into the $n$-hexane and ethyl acetate fractions. Secondary metabolites in the $\mathrm{n}$-hexane fraction are usually compounds from the steroids, triterpenoids, and long-chain compounds from the alcoholic, alkane, and fatty acid groups. These compounds have no antioxidant activity. Hydroxyl groups in non-polar compounds are not able to reduce DPPH radicals. The antioxidant activity of an extract or fraction can be classified into three groups, namely strong $\left(\mathrm{IC}_{50}<200 \mu \mathrm{g} / \mathrm{mL}\right)$, active (IC 50 200-1000 $\mu \mathrm{g} / \mathrm{mL}$ ), and inactive $\left(\mathrm{IC}_{50}>1000 \mu \mathrm{g} / \mathrm{mL}\right)$ (Fadhillah, Elfita, Muharni, Yohandini, \& Widjajanti, 2019).

Isolation of pure compounds from the fraction of methanol obtained compounds 1 and 2. Molecular structure was determined by spectroscopic methods (NMR) and compared with literature data. The 'H-NMR spectrum of compound 1 is shown in Figure 1 . In the $\mathrm{H}$ NMR spectrum of compound 1 (Figure 1 and Table 2), five proton signals are present in chemical shifts above $6.00 \mathrm{ppm}$, each of the signals has the integrity of one proton. The signals indicate that all protons of compound 1 are aromatic protons. The characteristic flavonoid is seen in the spectrum, namely the presence of five protons bound to rings $A$ and $B$. The proton signal is present at $\delta_{\mathrm{H}} 6.18(1 \mathrm{H}, \mathrm{d}, \mathrm{J}=2.5 \mathrm{~Hz}) ; 6.39(1 \mathrm{H}, \mathrm{d}, \mathrm{J}$ $=2.5 \mathrm{~Hz}) ; 6.88(1 \mathrm{H}, \mathrm{d}, \mathrm{J}=8.5 \mathrm{~Hz}) ; 7.64(1 \mathrm{H}, \mathrm{dd}, \mathrm{J}=$ $8.5 ; 2.5 \mathrm{~Hz})$; and $7.74 \mathrm{ppm}(1 \mathrm{H}, \mathrm{d}, \mathrm{J}=2.5 \mathrm{~Hz})$.

Based on the multiplicity pattern, the proton aromatic has three types of signals as doublet ortho (do), doublet meta $(\mathrm{dm})$, and ortho - meta coupling doublet doublet (dodm). The signals indicate that two aromatic protons are bound on ring $A\left(\delta_{H} 6.18\right.$ and $\left.6.39 \mathrm{ppm}\right)$ and three protons on ring $B\left(\delta_{H} 6.88 ; 7.64 ;\right.$ and $\left.7.74 \mathrm{ppm}\right)$. Thus, ring $B$ is classified as dioxygenated. The oxygenation position 2,4 or 3,4 can be identified from the chemical shifts of the three protons and their multiplicity. The signal of the proton has an accumulated chemical shift and the multiplicity of do, dm, and dodm exchange between the two groups of protons. The multiplicity of the signals indicates that the compound as a flavonol group (Elfita et al., 2020).

Table 1. The $\mathrm{IC}_{50}$ values of antioxidant activity of $S$. samarangense

\begin{tabular}{lc}
\hline Test samples & $\mathrm{IC}_{50}(\mu \mathrm{g} / \mathrm{mL})$ \\
\hline $\mathrm{n}$-Hexane fraction & $>1000$ \\
Ethyl acetate fraction & 89.67 \\
Methanol fraction & 31.83 \\
Compound 1 & 11.16 \\
Compound 2 & 11.43 \\
Ascorbic acid & 10.22 \\
\hline
\end{tabular}

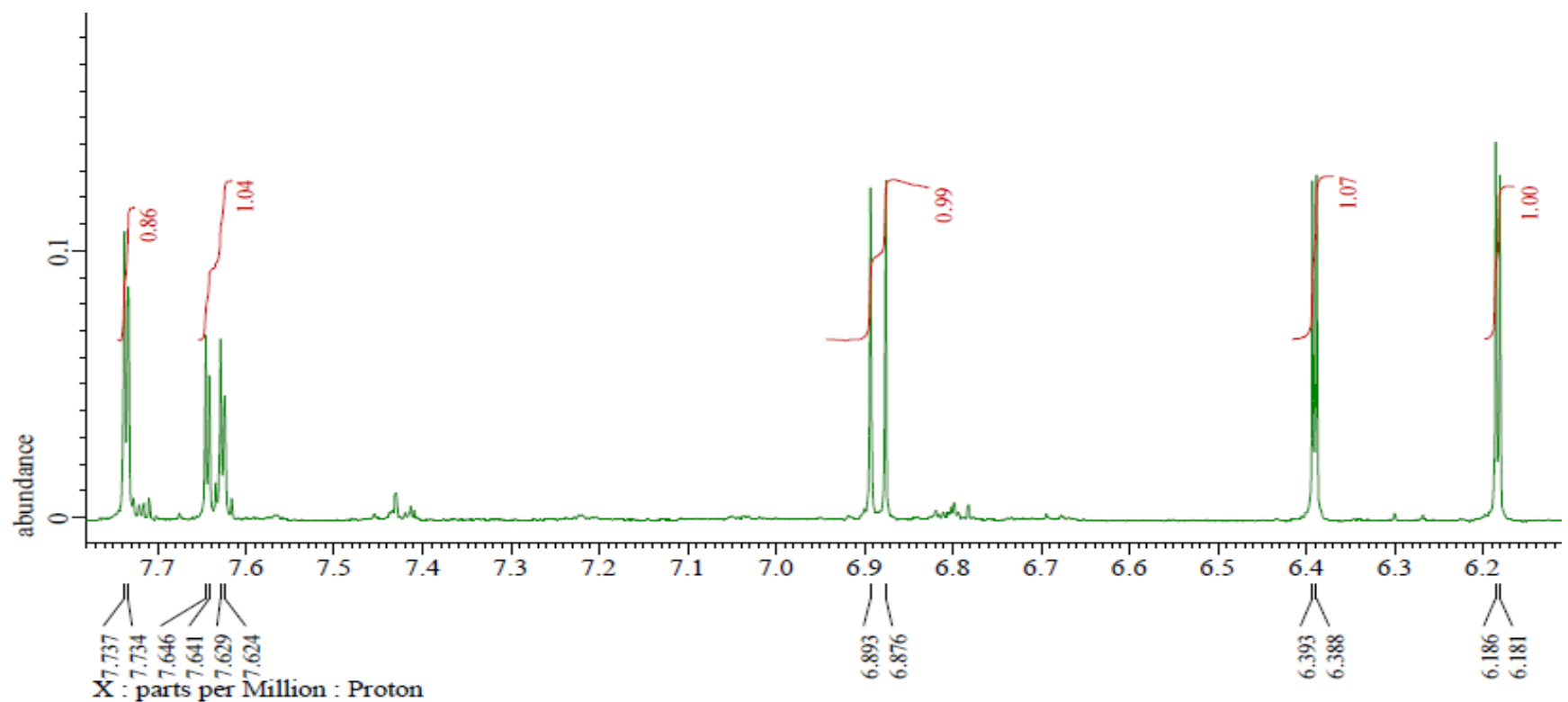

Figure 1. The ${ }^{1} \mathrm{H}-\mathrm{NMR}$ spectrum of compound $1\left({ }^{1} \mathrm{H}-500 \mathrm{MHz}\right.$, in $\left.\mathrm{CD}_{3} \mathrm{OD}\right)$ 
The ${ }^{13} \mathrm{C}-\mathrm{NMR}$ spectrum (Figure 2) showed the presence of 15 carbon signals for the flavonol. This compound 1 as flavonol indicated the presence of carbonyl carbon signals at $\delta_{c} 177.4 \mathrm{ppm}$. The spectrum of compound 1 revealed seven oxyaryl (= C-O) carbon atoms at $\delta_{c}$ 137-166 ppm. The signals indicated the presence of five hydroxyl groups attached on flavonoids, two hydroxyl groups in the $A$ and $C$ and one hydroxyl groups in the $B$ rings. The characteristics of the -OH chelate signal on $\mathrm{C}-5$ and carbon carbonyl chelates on C-4 do not appear in this spectrum because in $\mathrm{CD}_{3} \mathrm{OD}$. Spectrum data from the literature (Table 2) in DMSO solvents so that hydroxyl protons appear on the spectrum (Zhang, Wang, Yang, Zhou, \& Zhang, 2014).

A literature search showed that the ${ }^{1} \mathrm{H}$ and ${ }^{13} \mathrm{C}$ NMR data, compound 1 has five hydroxyl substitution pattern of one of the aromatic rings of the flavonoid moiety. The HMQC and HMBC spectrum indicated that position C- 6 and $\mathrm{C}-8$ at ring $A$ had to be the unsubstituted one, as evident from the correlations between $\mathrm{H}-6\left(\delta_{\mathrm{H}} 6.18\right)$ with 162.6 (C-5); 165.7 (C-7); 94.5 (C-8); 104.5 (C$10)$ and the correlations between $\mathrm{H}-8\left(\delta_{\mathrm{H}} 6,39\right)$ with 165.7 (C-7); 99.3 (C-6); 104.5 (C-10). The Carbon at C-3' dan $\mathrm{C}-4^{\prime}$ in ring $\mathrm{B}$ had to be the substituted one with hydroxyl group. The next hydroxyl group is attached to $\mathrm{C}-3$ of the ring $\mathrm{C}$ of the flavonoid moiety.

The identification of carbon and proton signals base on analysis $\mathrm{HMQC}, \mathrm{HMBC}, \mathrm{COSY}$, and compared with literature (Zhang et al., 2014), listed in Table 2. Based on spectrum analysis and compared with literature (Zhang et al., 2014), compound 1 was identified as quercetin. The molecular formula $\mathrm{C}_{15} \mathrm{H}_{10} \mathrm{O}_{7}$, with $\mathrm{DBE}$ $=11$. The $\mathrm{HMBC}$ correlation and C-assignment of compound 1 showed in Figure 4.

In the ${ }^{1} \mathrm{H}-\mathrm{NMR}$ spectrum of compound 2 (Figure 5) showed the presence of a single proton signal in the aromatic region at $\delta_{H} 7.03 \mathrm{ppm}$ with singlet multiplicity. The signal indicates that compound $\mathbf{2}$ has aromatic protons, which are all equivalent. In the ${ }^{13} \mathrm{C}-\mathrm{NMR}$ spectrum showed the presence of five signals, namely four aromatic carbon and one acid carbonyl signals. The intensity of the signal at $\delta_{c} 110.4 \mathrm{ppm}(\mathrm{CH})$ is high, which indicates the presence of two equivalent carbon methine. Besides, the signals of carbon quarternary with a higher intensity than other carbon quarternary appear at $\delta_{C} 146.5 \mathrm{ppm}$. This signal indicates that the carbon is equivalent. The ${ }^{13} \mathrm{C}$-NMR spectrum in Figure 5 shows that compound 2 has two equivalent carbon groups, namely carbon methine and carbon quarternary. The total carbon of compound $\mathbf{2}$ is seven carbons, i.e., six aromatic carbon and one carbonyl carbon. The chemical shift values shown in Table 3 indicate the presence of three carbon oxyaryl $(=\mathrm{C}-\mathrm{O})$, namely at $\delta_{\mathrm{C}}$ 137.8; 144.9; and $144.9 \mathrm{ppm}$. Furthermore, the spectrum of compound 2 was compared with the spectrum in the literature (Table 3 ). The compound 2 was identified as gallic acid.

Table 2. The NMR data of compound $1\left({ }^{1} \mathrm{H}-500 \mathrm{MHz},{ }^{13} \mathrm{C}-125 \mathrm{Mhz}\right.$, in $\mathrm{CD}_{3} \mathrm{OD}$ ) and $1^{*}$ (quercetin, ${ }^{1} \mathrm{H}-500$ $\mathrm{MHz},{ }^{13} \mathrm{C}-125 \mathrm{Mhz}$, in DMSO, ppm)

\begin{tabular}{|c|c|c|c|c|c|c|}
\hline $\begin{array}{l}\text { No. } \\
\text { C }\end{array}$ & $\begin{array}{c}\delta c \\
(p p m) \\
1\end{array}$ & $\begin{array}{c}\delta_{H}(\mathrm{ppm}), \Sigma \mathrm{H}, \\
\text { multiplicity, } J(\mathrm{~Hz}) \\
1\end{array}$ & $\begin{array}{c}\mathrm{HMBC} \\
1\end{array}$ & $\begin{array}{c}\operatorname{COSY} \\
1\end{array}$ & $\begin{array}{c}\delta c \\
(\mathrm{ppm}) \\
1^{*}\end{array}$ & $\begin{array}{c}\delta_{\mathrm{H}}(\mathrm{ppm}), \Sigma \mathrm{H}, \text { multiplicity, } J \\
\left(\mathrm{H}^{*}\right)\end{array}$ \\
\hline 2 & 148.1 & & & & 147.3 & \\
\hline 3 & 137.4 & & & & 136.1 & \\
\hline 4 & 177.4 & & & & 176.3 & \\
\hline 5 & 162.6 & & & & 161.1 & $12.47(\mathrm{br}, \mathrm{s})$ \\
\hline 6 & 99.3 & $\begin{array}{l}6.18(1 \mathrm{H}, \mathrm{d}, \\
\mathrm{J}=2.5)\end{array}$ & $\begin{array}{l}162.6(C-5) ; 165.7(C-7) ; 94.5 \text { (C- } \\
\text { 8): } 104.5(C-10)\end{array}$ & & 98.65 & $6.19(1 \mathrm{H}, \mathrm{d}, \mathrm{J}=2.1)$ \\
\hline 7 & 165.7 & & & & 164.3 & $10.93(1 \mathrm{H}, \mathrm{s})$ \\
\hline 8 & 94.5 & $\begin{array}{l}6.39(1 \mathrm{H}, \mathrm{d} \\
\mathrm{J}=2.5)\end{array}$ & $\begin{array}{l}165.7(\mathrm{C}-7) ; 99.3(\mathrm{C}-6) ; 104.5 \text { (C- } \\
10)\end{array}$ & & 93.8 & $6.42(1 \mathrm{H}, \mathrm{d}, \mathrm{J}=2.1)$ \\
\hline 9 & 158.3 & & & & 156.6 & \\
\hline 10 & 104.5 & & & & 103.4 & \\
\hline $1^{\prime}$ & 124.2 & & & & 122.4 & \\
\hline $2^{\prime}$ & 116.1 & $\begin{array}{l}7.74(1 \mathrm{H}, \mathrm{d} \\
\mathrm{J}=2.5)\end{array}$ & $\begin{array}{l}146.3\left(C-3^{\prime}\right) ; 148.9\left(C-4^{\prime}\right) ; 121.8 \\
\left(C-6^{\prime}\right) ;\end{array}$ & & 115.5 & $7.66(1 \mathrm{H}, \mathrm{d}, \mathrm{J}=2.1)$ \\
\hline $3^{\prime}$ & 146.3 & & & & 145.5 & $9.35(\mathrm{~s})$ \\
\hline $4^{\prime}$ & 148.9 & & & & 148.1 & $9.69(\mathrm{~s})$ \\
\hline $5^{\prime}$ & 116.3 & $\begin{array}{l}6.88(1 \mathrm{H}, \mathrm{d} \\
J=8.5)\end{array}$ & $\begin{array}{l}146.3\left(C-3^{\prime}\right) ; 148.9\left(C-4^{\prime}\right) ; 124.2 \\
\left(C-1^{\prime}\right)\end{array}$ & 7.64 & 116.0 & $6.88(1 \mathrm{H}, \mathrm{d}, \mathrm{J}=8.4)$ \\
\hline $6^{\prime}$ & 121.8 & $\begin{array}{l}7.64(1 \mathrm{H}, \mathrm{dd}, \\
\mathrm{J}=8.5 ; 2.5)\end{array}$ & $116.1\left(\mathrm{C}-2^{\prime}\right) ; 148.9\left(\mathrm{C}-4^{\prime}\right)$ & 6.88 & 120.5 & $7.53(1 \mathrm{H}, \mathrm{dd}, \mathrm{J}=8.4 ; 2.1)$ \\
\hline
\end{tabular}

Note: * Zhang et al., 2014 


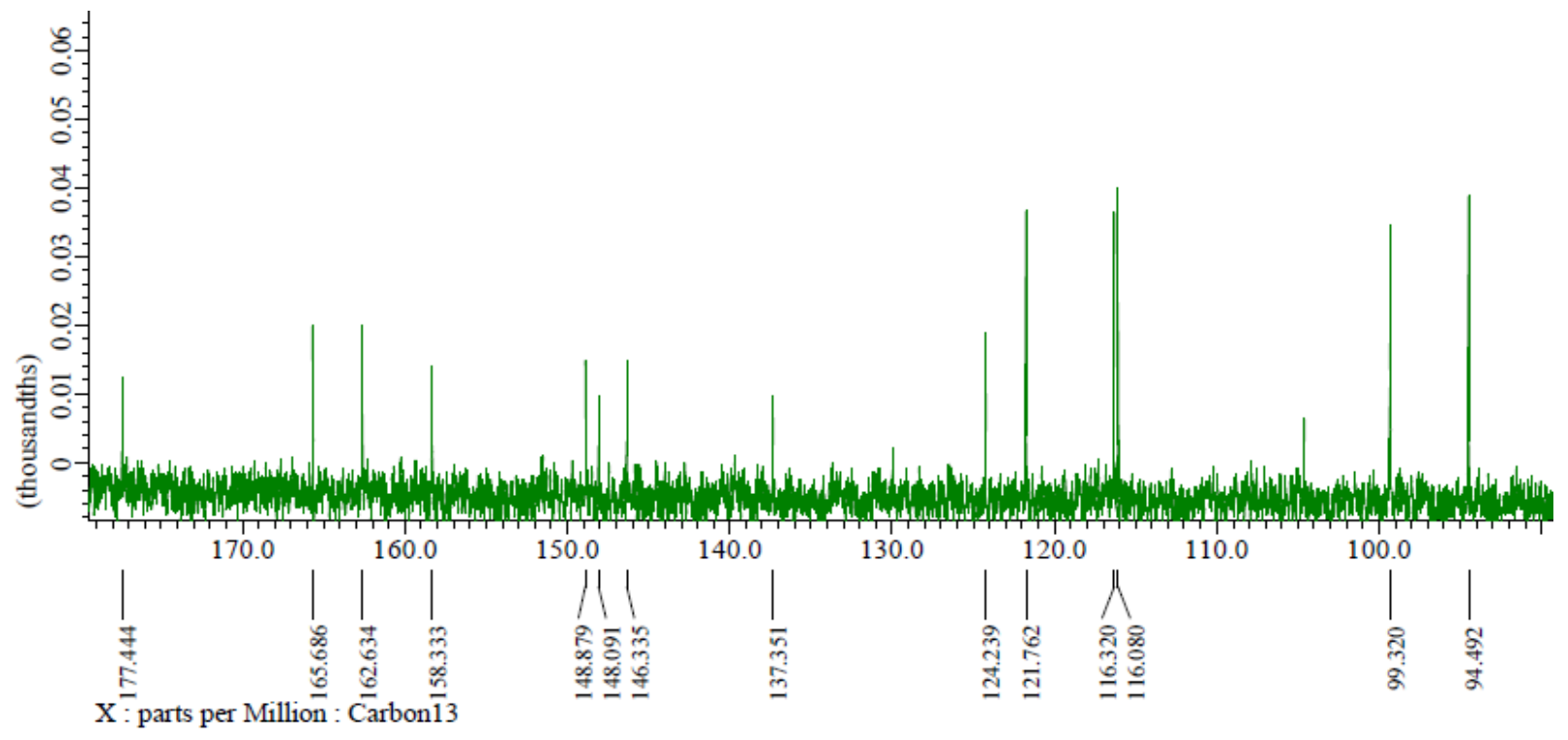

Figure 2. The ${ }^{13} \mathrm{C}-\mathrm{NMR}$ spectrum of compound $1\left({ }^{13} \mathrm{C}-125 \mathrm{MHz}\right.$, in $\left.\mathrm{CD}_{3} \mathrm{OD}\right)$

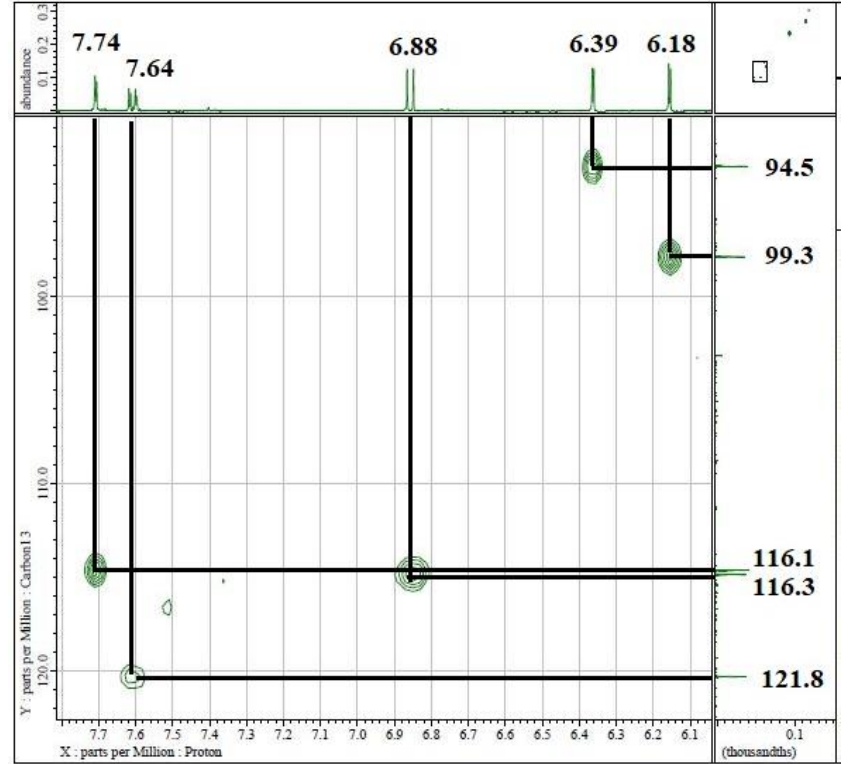

A

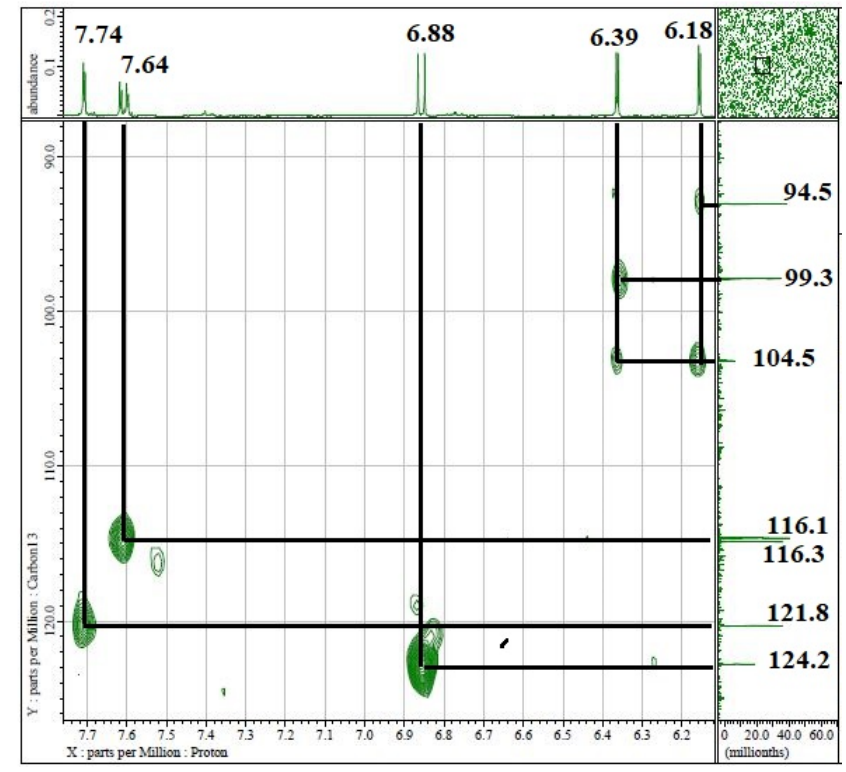

B

Figure 3. The spectra of compound 1, $\mathrm{HMQC}$ (A) and $\mathrm{HMBC}$ (B) $\left({ }^{1} \mathrm{H}-500 \mathrm{MHz},{ }^{13} \mathrm{C}-125 \mathrm{MHz}\right.$, in $\left.\mathrm{CD}_{3} \mathrm{OD}\right)$

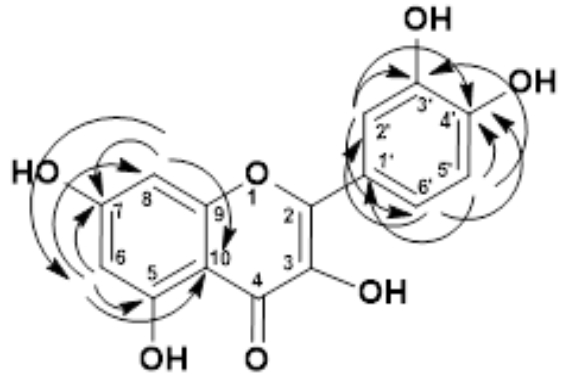<smiles>O=c1c(O)c(-c2ccc(O)c(O)c2)oc2cc(O)cc(O)c12</smiles>

Figure 4. The $\mathrm{HMBC}$ correlation and C-assignment of quercetin 

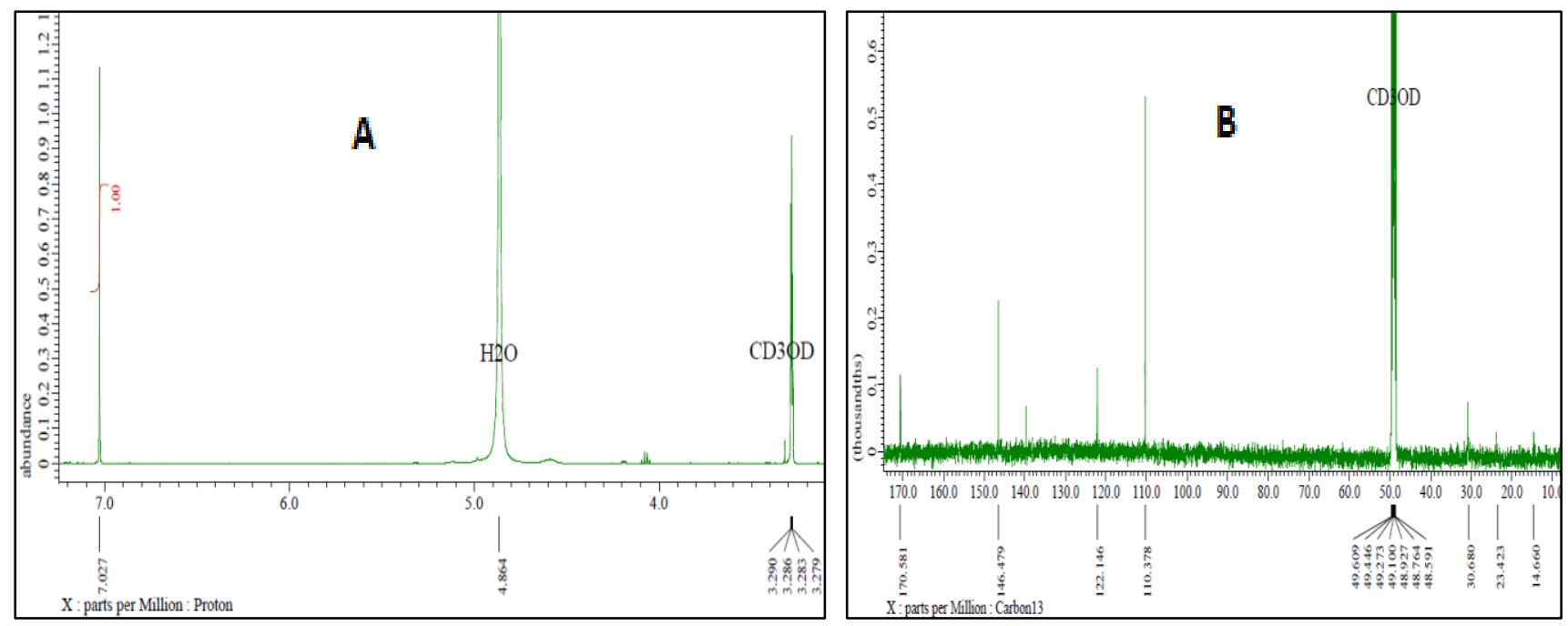

Figure 5. The ${ }^{1} \mathrm{H}$ and ${ }^{13} \mathrm{C}-\mathrm{NMR}$ spectrum of compound $2\left({ }^{1} \mathrm{H}-500 \mathrm{MHz},{ }^{13} \mathrm{C}-125 \mathrm{Mhz}\right.$, in $\left.\mathrm{CD}_{3} \mathrm{OD}\right)$

Table 3. ${ }^{1} \mathrm{H}$ and ${ }^{13} \mathrm{C}$ NMR data of compound $2\left({ }^{1} \mathrm{H}-500 \mathrm{MHz},{ }^{13} \mathrm{C}-125 \mathrm{Mhz}\right.$, in $\left.\mathrm{CD}_{3} \mathrm{OD}\right)$ and $2^{*}$ (gallic acid, ${ }^{1} \mathrm{H}-500 \mathrm{MHz},{ }^{13} \mathrm{C}-125 \mathrm{Mhz}$, in $\mathrm{CDCl}_{3}$ )

\begin{tabular}{ccccc}
\hline No. C & $\begin{array}{c}\boldsymbol{\delta}_{\mathrm{C}}(\mathrm{ppm}) \\
\mathbf{2}\end{array}$ & $\begin{array}{c}\boldsymbol{\delta}_{\mathrm{H}}(\mathrm{ppm}), \boldsymbol{\Sigma} \mathrm{H}, \\
\text { multiplicity, } \boldsymbol{J}(\mathrm{Hz})\end{array}$ & $\begin{array}{c}\boldsymbol{\delta}_{\mathrm{C}}(\mathrm{ppm}) \\
\mathbf{2}^{*}\end{array}$ & $\begin{array}{c}\boldsymbol{\delta}_{\mathrm{H}}(\mathrm{ppm}), \boldsymbol{\Sigma} \mathrm{H}, \text { multiplicity, } \\
\mathbf{2}(\mathrm{Hz}) \\
\mathbf{2}^{*}\end{array}$ \\
\hline 1 & 122.1 & & 120.5 & \\
2 & 110.4 & $7.03(1 \mathrm{H}, \mathrm{s})$ & 108.8 & $7.10(1 \mathrm{H}, \mathrm{s})$ \\
3 & 146.5 & & 145.5 & \\
4 & 139.0 & & 138.1 & \\
5 & 146.5 & & 145.5 & $7.10(1 \mathrm{H}, \mathrm{s})$ \\
6 & 110.4 & $7.03(1 \mathrm{H}, \mathrm{s})$ & 108.8 & \\
7 & 170.6 & & 167.6 & \\
\hline
\end{tabular}

Note: * Abri \& Maleki, 2016
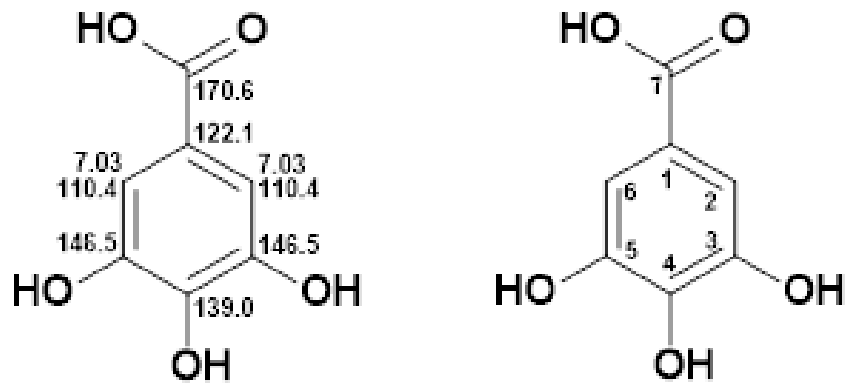

Figure 6. The $\delta$ and C-assignment of galic acid

Based on spectrum analysis of compound 2 and compared with literature (Abri \& Maleki, 2016), compound 2 was identified as gallic acid. The molecular formula $\mathrm{C}_{7} \mathrm{H}_{6} \mathrm{O}_{5}$, with $\mathrm{DBE}=5$. The $\delta$-assignment of compound 2 showed in Figure 6.

The antioxidant activity data (Table 1) shows that compounds 1 and 2 have the equivalent activity of ascorbic acid. The antioxidant activity of a compound can be classified as strong $\left(\mathrm{IC}_{50}<10 \mu \mathrm{g} / \mathrm{mL}\right)$ active $\left(\mathrm{IC}_{50}\right.$ $<100 \mu \mathrm{g} / \mathrm{mL}$ ), and inactive $\left(\mathrm{IC}_{50}>100 \mu \mathrm{g} / \mathrm{mL}\right)$. It was also reported that antioxidant compounds with $\mathrm{IC}_{50}$ values $\leq 11.4 \mu \mathrm{g} / \mathrm{mL}$ were classified as strong (Minami et al., 1994; Deachathai et al., 2006). 


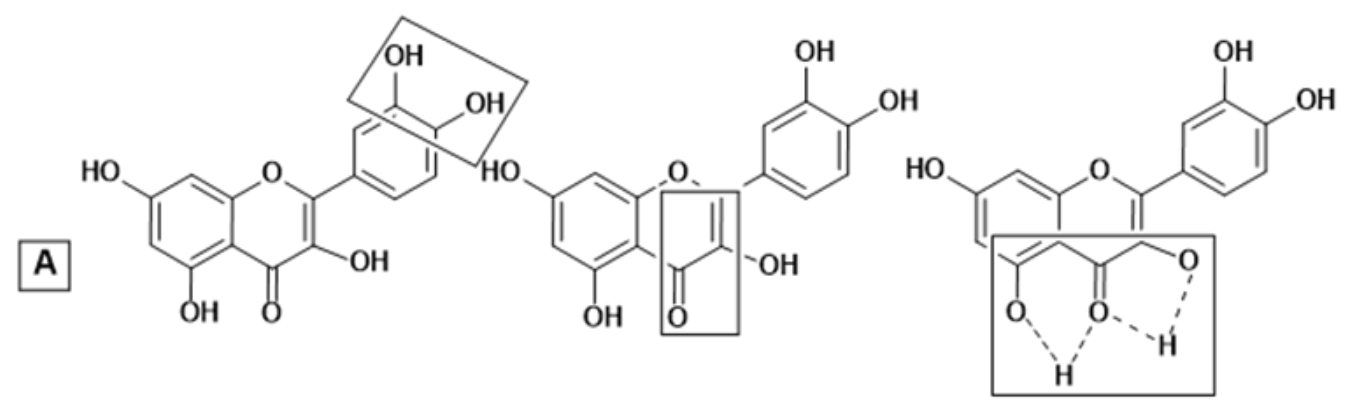<smiles>O=C(O)c1cc(O)c(O)c(C23CC4CC(CC(C4)C2)C3)c1</smiles>

Figure 7. The summary structure of quercetin (A) and gallic acid (B) which provide efficient radical scavenging<smiles>C=COC1C=C(C(=O)O)C=C(O)C1=O</smiles>

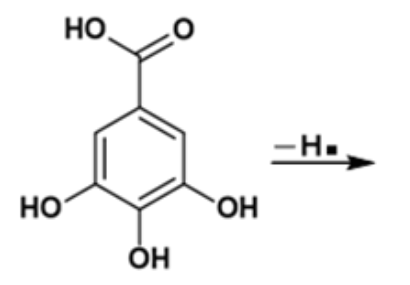<smiles>O=C(O)c1cc(O)c(O)c(O)c1</smiles><smiles>O=C(O)c1cc(O)c2c(c1)O[CH]O2</smiles>

Figure 8. The description of the stabilization of gallic acid free radicals by the formation of intramolecular hydrogen bonds, a diketone, distribution, and delocalization of electrons

Compound 1 is strong antioxidant by the DPPH method $\left(\mathrm{IC}_{50} 11.16 \mu \mathrm{g} / \mathrm{mL}\right)$. The strong antioxidant activity due to the compound 1 has a catechol unit on ring $B$, the conjugation on the $C$ ring (between 2,3 double bonds with a 4 -oxo function), the presence of hydroxyl groups at positions $\mathrm{C}-3^{\prime}$ and $\mathrm{C}-5^{\prime}$ providing hydrogen bonding to the oxo group (Figure 7). The presence of the groups causes the radicals produced can be stabilized by distribution and delocalization electron (Procházková, Boušová, \& Wilhelmová, 2011; Brunetti et al., 2013). The compounds that have catechol or 1,2dihydroxy phenyl units are more easily subjected to proton abstraction by free radicals to form more stable free radicals. This stability is caused by the resulting free radicals, which can form intramolecular hydrogen bonds with the neighboring hydroxyl group and form a diketone (Sawai \& Sakata, 1998). The main structural features of quercetin and galic acid required for efficient radical scavenging could be summarized as Figure 8 .

Compound 2 is strong antioxidant by the DPPH method $\left(\mathrm{IC}_{50} \quad 11.43 \mu \mathrm{g} / \mathrm{mL}\right)$. The strong antioxidant activity due to the gallic acid has three hydroxyl groups that form two catechol units. Proton abstraction of gallic acid by free radicals is much easier, and new free radicals are formed more stable because of the presence of two catechol units in one ring (Sawai \& Sakata, 1998). The description of the stabilization of gallic acid free radicals by the formation of intramolecular hydrogen bonds, a diketone, distribution, and delocalization of electrons, is shown in Figure 6. 


\section{CONCLUSIONS}

In this study, two compounds were obtained from the methanol fraction of the stem bark of $S$. samarangense, namely quercetin and gallic acid. Both of these compounds have strong antioxidant activity, which is equivalent to a positive control (ascorbic acid). Thus the use of the stem bark of $S$. samarangense by the Ogan ethnic community in South Sumatra to treat hypertension is scientific.

\section{ACKNOWLEDGMENTS}

The authors deliver high gratitude to Sriwijaya University for funding this research by Penelitian Unggulan Profesi 2019, with contract no. 0144.21/UN9/SB3.LP2M.PT/2019

\section{REFERENCES}

Abri, A., \& Maleki, M. (2016). Isolation and identification of gallic acid from the Elaeagnus angustifolia leaves and determination of total Phenolid, flavonoids contents and investigation of antioxidant activity. Iranian Chemical Communication, 4, 146-154.

Brunetti, C., Martina, D., Ferdinando, M.D., Fini, A., Pollastri, S., \& Tattini, M. (2013). Flavonoids as antioxidants and developmental regulators: relative significance in plants and humans. International Journal of Molecular Sciences, 14, 3540-3555.

Budiono, B., Elfita, E., Muharni, M., Yohandini, H., \& Widjajanti, H. (2019). Antioxidant activity of Syzygium samarangense $\mathrm{L}$. and their endophytic fungi. Molekul, 14(1), 48-55.

Chandra, P. \& Daljit Singh Arora, D.S. (2017). Antioxidant compounds derived from plants, description and mechanism of phytochemicals. Journal of Agroecology and Natural Resource Management, $4(1), 55-59$.

Chikezie, P.C., Ibegbulem, C.O., \& Mbagwu, F.N. (2015). Bioactive principles from medicinal plants. Research Journal of Phytochemistry, 9, 88115.

Deachathai, S., Mahabusaracam, W., Phongpacichit, S., Taylor, W. C., Zhang, Y. J., \& Yang, C.R. (2006). Phenolic compound from the flowers of Garcinia dulcis. Phytochemistry, 67, 464-469.

Elfita, E., Supriyatna, S., Bahti, H,H., \& Dachriyanus, D. (2011). A structure-activity study of antioxidant compounds from the stem bark of kandis gajah (Garcinia griffithii T. Anders). Jurnal Ilmu Kefarmasian Indonesia, 9(1), 35-39.

Elfita, E., Mardiyanto, M., Fitrya, F., Larasati, J.E., Julinar, J., Widjajanti, H., Muharni, M. (2019). Antibacterial activity of Cordyline fruticosa leaf extracts and its endophytic fungi extracts. Biodiversitas, 20(12), 3804-3812.

Elfita, E., Muharni, M., Mardiyanto, M., Fitrya, F., Fera, F., Widjajanti, H. (2020). Antibacterial activity of traditional medicine Scurrula atropurpurea (BL) DANS and their endophytic fungi. Key Engineering Materials, 840, 205-213.

Fadhillah. F., Elfita, E., Muharni, M., Yohandini, H., \& Widjajanti, H. (2019). Chemical compound isolated from antioxidant active extract of endophytic fungus Cladosporium tenuissimumin in Swietenia mahagoni leaf stalks. Biodiversitas, 20(9), 2645-2650.

Figueiredo, E.A., Alves, N.F.B., Monteiro, M.M.O., Cavalcanti, C.C., Silva, T.M.S., Silva, T.M.G., Brage, V.A \& Oliveira, E.J. (2017). Antioxidant and antihypertensive effects of a chemically defined fraction of syrah red wine on spontaneously hypertensive rats. Nutrients, 9(574), 1-15.

Gayen, P.R., Hossain, A.S.M., Saifuzzaman, Md., \& Faroque, A.B.M. (2016). Anthelmintic Activity of ethanolic extract of Syzygium samarangense (Blume) Merril \& Perry. Journal of Pharmaceutical Sciences, 15(1), 109-111.

Jayasinghe, U.L.B., Ratnayake, R.M.S., Medawals., M.M.W.S., \& Fujimoto, Y. (2007). Dihydrochalcone with radical scavenging properties from the leaves of Syzygium jambos. Natural Product Research, $21(6), 551-554$.

Khandakar, M.M. \& Boyce, A.N. (2016). Growth, distribution and physiochemical properties of wax apple (Syzygium samarangense). Australian Journal of Crop Science, 10(12), 1640-1648.

Kizhakekuttu \& Widlansky. (2010). Natural antioxidants and hypertension: promise and challenges. Cardiovascular Therapeutics, 28(4), 20-32.

Loperena, R., \& Harrison, D.G. (2017). Oxidative stress and hypertension diseases. Medical Clinics of North America, 101(1), 169-193.

Minami, H., Kinoshita, M., Fukuyama, Y., Kodama, M., Yoshizawa, T., Suigura, M., Nakagawa, K., \& Tago, H. (1994). Antioxidant xanthones from Garcinia subelliptica. Phytochemistry, 36, 501506.

Muharni, M., Elfita, E., \& Amanda, A. (2011). Biflavonoid compound from the stem bark of gamboge (Garcinia xanthochymus). Indonesian Journal of Chemisty, 11 (2), 169 - 173.

Muharni, M., Elfita, E., Yohandini, H., Julinar, J., Yasrina, Y., \& Miranti, M. (2019). Chemical constituents from stem bark of Flacourtiarukam Zoll. \& Mor. and their antioxidant activities. Sains Malaysiana, 48, 1899-1906. 
Nadeem, M., Abbasi, B.H., Younas, M., Ahmad, W., \& Khan, T. (2017). A review of the green syntheses and anti-microbial application of gold nanoparticles. Green Chemistry Letters and Reviews, 10(4), 216-227.

Procházková, D., Boušová, I., \& Wilhelmová, N. (2011). Antioxidant and prooxidant properties of flavonoids. Fitoterapia, 82, 513-523.

Sawai, Y., \& Sakata, K. (1998). NMR analytical approach to clarify the antioxidative molecular mechanism of catechins using 1,1-Diphenyl-2picrylhydrazyl.

Journal of Agricultural and Food Chemistry, 46, 111114.

Saxena, M., Saxena, J., Nema, R., Singh, D., \& Gupta, A. (2013). Phytochemistry of medicinal plants. Journal of Pharmacognosy and Phytochemistry, $1(6), 168-182$.

Sheela, D \& Cheenickal. (2017). Total phenolics and flavonoids among the selected species of
Syzygium, Gaertn. Res. Journal of Pharmacognosy and Phytochemistry, 9, 101-104.

Shyamapada \& Manisha. (2015). Coriander (Coriandrum sativum L.) essential oil: chemistry and biological activity. Asian Pacific Journal of Tropical Biomedicine, 3(3), 1-8.

Widiasari, S. (2018). Mekanisme inhibisi angiotensin converating enzym oleh flavonoid pada hipertensi. Collaborative Medical Journal (CIM), $1(2), 1-5$.

Yang, J., Su, J.C., Lei, X.P., Huang, X.J, Zhang, D.M., Ye, W.C., \& Wang, Y. (2018). Acylphloroglucinol derivatives from the leaves of Syzygium samarangense and their cytotoxic activites. Fitoterapia, 12(9), 1-6.

Zhang, Y., Wang, D., Yang, L., Zhou, D., \& Zhang, J. (2014). Purification and characterization of flavonoids from the leaves of Zanthoxylum bungeanum and correlation between their structure and antioxidant activity. PLOS ONE, 9(8), $1-11$. 